\title{
Guilt and Shame in Chinese Culture: A Cross-cultural Framework from the Perspective of Morality and Identity
}

\section{OLWEN BEDFORD AND KWANG-KUO HWANG}

The emotions of guilt and shame are pervasive in daily life. They help maintain a sense of personal identity (Hultberg, 1988; Scheff, 1988), function as mechanisms of social control (Creighton, 1988), and provide channels for processing stress or norm violation into self-punishment (Lebra, 1988). Guilt and shame subtly shape behavior, often by causing people to behave so as to avoid experiencing them. It is unlikely that any society could be maintained without them (Creighton, 1988).

There is considerable empirical and theoretical agreement that the subjective experience of guilt is accompanied by feelings of violation of the moral order and responsibility for negative outcome (DeRivera, 1984; Lindsay-Hartz, 1984). If responsibility is not accepted and there is only fear of the consequences of the action, then guilt is not experienced in the true sense. In order to feel guilt, an individual must first of all (rightly or wrongly) bear some feeling of responsibility for the transgression (Izard, 1977). Following from this relationship between guilt and responsibility, there are four propositions that have a logical connection to guilt (Bedford, 1990): belief in the possibility to have acted otherwise, acceptance of the legitimacy of blame and punishment, hope of atonement, and the inability to cause another to feel guilt. If guilt is necessarily connected to responsibility, then it is not possible to put other persons into a state of guilt unless they are willing or capable of accepting responsibility. The inability to place persons in a state of guilt without their accepting responsibility makes guilt a suitable basis for a system of morality. In fact, research has suggested Americans experience guilt as a moral transgression (DeRivera, 1984; Lindsay-Hartz, 1984).

While guilt is felt over one's actions, shame is felt over who one is (Wharton, 1990; Tangey, 1998). Guilt refers to wrongdoing, or violation of some sort of rule or internal law, and leads to counterfactual thinking of how to alter one's actions to undo the situation (Niedenthal, Tangey, \& Gavanski, 1994). In guilt, one's self-image remains intact (Lindsay-Hartz, 1984). In shame, one's self-image is brought into question (Lewis, 1987; Wurmser, 1981). Shame is always linked 
to judgments about the self, and related to the sense of self and personal identity (Babcock \& Sabini, 1990; Hultberg, 1988; Thrane, 1979). It can lead to counterfactual thinking of how to alter qualities of the self in order to undo the shame (Niedenthal, Tangey, \& Gavanski, 1994). It serves to protect the integrity of individual identity and also protects the social order by ensuring conformity. Phenomenologically, shame is the feeling of loss of standing in the eyes of oneself or significant others and can occur as the result of a failure to live up to expectations for a person of one's role or status. It entails not merely the feeling of having lost status, but the conviction that one is really not who one thought one was - the failure to achieve a wished-for self-image (Creighton, 1988), the failure to live up to an ego ideal (Kaufman, 1989; Piers \& Singer, 1953), or perhaps even the revelation that one embodies a negative ideal (Lindsay-Hartz, 1984). A number of characteristic self- and body-images may accompany feelings of shame. Most central are the feelings of exposure (Hultberg, 1988), inadequacy (LindsayHartz, 1984; Miller, 1985; Morrison, 1983), alienation (Morrison, 1983), and anger (Lewis, 1971; Lansky, 1987), particularly inward anger (Lutwak, Panish, Ferrari \& Razzino, 2002). Since shame is not necessarily connected with responsibility, it may be experienced because of events or situations over which one has no control, and thus may be imposed on others. For this reason, it has not been considered an appropriate basis for morality (Babcock \& Sabini, 1990; Hultberg, 1988; Thrane, 1979).

In sum, guilt is felt over questionable actions and entails the feeling of responsibility for transgression. Shame is felt when identity is called into question and has no such necessary connection with responsibility. Because of the connection with responsibility, moral transgressions have generally been considered more closely linked to guilt than shame.

Influenced by social Darwinism in the 1900s, Western academic thought has subscribed to the idea of progression in the development of both individuals and cultures from simple to more complex forms. According to Babcock and Sabini (1990), early conceptions of shame by psychoanalysts and anthropologists characterized it as an immature emotion in contrast to the more mature emotion, guilt. This notion was reinforced by the observation that shame developmentally precedes guilt (Walter, 2002). Guilt was assumed to be the adult emotion of self control, and shame was understood to be a childish regression.

The tendency to view guilt as a more highly civilized and advanced emotion than shame remains. A number of recent studies have associated shame with negative traits or behaviors, while guilt has been associated with positive impact. For example, a recent study linked avoidance of responsibility with shame and nonavoidance of responsibility with guilt, with the conclusion that nonavoiders are more socially competent (Walter, 2002). A study of Japanese college students found that guilt has a socially adaptive function, but that shame is associated with maladaptive behaviors (Kohki, 2002). Similarly, a study of American undergraduates found that guilt improved relationship outcomes while shame harmed 
them (Leith \& Baumeister, 1998). A study of the relation between religiosity and shame and guilt concluded that religious subjects "were more prone to guilt and reported higher feelings of empathy, which could be party due to their higher levels of guilt." The same study also reported possible evidence that religion could "attenuate the maladaptive effects on interpersonal and intrapersonal functioning of shame" (Luyten, Corveleyn, \& Fontaine, 1998, p. 165). A summary of research on guilt and shame concluded that

feelings of shame often give rise to a range of potentially destructive motivations, defenses, interpersonal behaviors, and psychological symptoms. In contrast, guilt appears to be the "quintessential" moral emotion serving numerous constructive "relationship-enhancing functions" without many of the burdens and costs inherent in feelings of shame. (Tangney, 2001, p. 127)

Although little research in the area of racial and ethnic differences in the experience of guilt and shame has been conducted, five points suggest the conceptualization of guilt and shame just described is likely to be problematic when applied to non-Western cultures: (1) Anthropologists have noted the relationship between guilt and shame and the roles they play in society differ cross-culturally (Benedict, 1947; Kluckhohn, 1960; Mead, 1937). (2) Proneness to experience guilt or shame may vary with cultural background. For example, Asian Americans have been found to be more shame-prone than their Caucasian counterparts (Szeto-Wong, 1997; Lutwak, Razzino, \& Ferrari, 1998). (3) Types of guilt and shame may differ across cultures. For example, specific Japanese patterns of guilt not recognized in Western cultures that are related to failure to achieve positive goals (De Vos, 1974), types of shame that may be unique to Eastern cultures (Sakuta, 1967), and discriminations in types of guilt and shame in Mandarin not possible in English (Bedford, 2002) have been identified. (4) Fundamental cross-cultural differences between Western and Eastern cultures in conceptualization of the self have been firmly established (Hofstede, 1980; Triandis, 1988, 1993, 1995). As guilt and shame are often characterized as emotions of self-evaluation or selfconscious emotions (e.g., Tangey \& Dearing, 2002; Tangey, 2002; Lewis, 1997; Cook, 1996; Abell \& Gecas, 1997), these fundamental differences in conceptualization of the self would likely be reflected in differences in the context, content, and even function of guilt and shame. (5) Finally, as mentioned, guilt and shame have been differentially linked to morality. However, evidence also strongly suggests broad differences in the moral systems of Eastern and Western cultures (Bedford, 1994; Hwang, 2001a). Differences in moral systems are likely reflected in a differential content and function of guilt and shame across cultures.

Given the overwhelming evidence to suggest the current conceptualization of guilt and shame is inadequate, a framework for understanding guilt and shame across cultures is clearly needed. This article formulates a cross-cultural framework of guilt and shame in relation to identity and morality in Western and Confucian cultures. First, identity is briefly examined in each culture, and then 
the relation between identity and morality illuminated. The role of guilt and shame in upholding the boundaries of identity and enforcing the constraints of morality is then discussed from the perspective of each culture. The developed framework is then applied to ethnographic data on the emotions of guilt and shame in Chinese culture and implications for future research discussed.

\section{IDENTITY IN THE WEST AND EAST}

The Judeo-Christian perspective on the origin of life suggests that individuals are created by God, and that all human beings are created equal. Based on this presumption, the boundaries around the individual self are defined as worthy of protection. Personality is defined within the individual who functions as an independent being, and the individual is the autonomous unit of action within the social group. Society from this point of view is seen as a collection of individuals, each of whom is a self-contained and, ideally, an almost self-sufficient entity. Personal goals are emphasized over group goals. Numerous studies support this characterization of individualistic cultures (Hofstede, 1980; Triandis, 1988).

An individualistic theory of human nature supposes that a person's interests are best served by permitting maximum freedom and responsibility for choosing objectives and the means for obtaining them. This belief is based on the assumption that the act of making choices contributes to the development of the individual and to the welfare of the society. Freedom is an important component of individualism, since individuality requires the liberty to develop one's potentials in one's own way.

In contrast, Confucian cultures emphasize that one's life is an inheritance from one's ancestors, just as one's children's lives flow from one's own. Family is conceptualized as the "great self" $(d a w o)$, and the boundaries of the self are flexible enough to include family members and significant others. It is this great self that an individual is obligated to protect against any threat from the outside, in contrast to the individual self of Western culture. Chinese identity is defined in terms of the system of relationships in which a person is involved (Triandis, Bontempo, Villareal, Asai, \& Lucca, 1988; Markus \& Kitayama, 1991). As a result, other personal relations may be treated as part of the self, and selfness is confirmed only through interpersonal relationships (Hamaguchi, 1982). Being a member of a group entails being held in esteem by that group, which in turn means that certain demands are made on one, and that one is entitled to make certain claims. These expectations are what confer value on the individual, so if status as a member is lost, status as a person is also lost. Personal identity is dependent on continued relations with the group.

The implication of relational identity is that behavior is evaluated according to how well it serves to enhance the interpersonal standards of society. Group oriented behavior such as harmonious interaction of group members is highly 
valued instead of individuality or individual freedoms as in Western cultures. No person ever has just cause to disrupt group harmony, as disruption impacts everyone's identity. Harmony is thus an important component of relational identity. Cultural emphasis on freedom versus harmony as crucial to the establishment and maintenance of identity has important implications for evaluation of behavior and conceptualization of rights.

\section{MORALITY WEST AND EAST}

Dwokin (1977) proposed that the moral codes of all cultures encompass personal rights, personal duties and social goals, but that there is a difference in the priority given to these three concepts. Western individualism is premised on the conception of personal rights, rather than personal duties or social goals. In contrast, Confucian ethics are based on concepts of personal duties and social goals rather than on personal rights. For example, Americans claim to have the right to individual freedoms. This claim is made not by virtue of citizenship in a country that grants these rights, but as individual human beings. It is based on the self evident truth that individuals own themselves, and that individuals are sovereign by reason of free will.

Belief in rights that exist irrespective of status or accomplishment reflects belief in objective standards that give definition to rights. Moral guidelines must be based on an objective standard because to assign values in a system that has no objective standards would mean subjecting oneself either to the arbitrary judgments of an authority figure who is also self-serving, or else to social convention, and the collectivity cannot be the source of wisdom not present in the individual. An objective standard is necessary so that one does not fall prey to deception. After all, facts do not tell one what to do; facts must be interpreted according to principles. Unless values are explicitly formulated into an objective standard one does not know what they are. If right and wrong are permitted to be purely a matter of subjective sentiment, then no action can be judged, since outside certification of sentiments is impossible. In sum, American emphasis on individual identity and freedom is consistent with priority on personal rights that are defined by objective standards.

Hwang (1995, 2001b) analyzed the deep structure of Confucianism by the method of structuralism and constructed a series of theoretical models on Confucian relationalism (Hwang, 1998, 2000) to illustrate the specific features of Chinese social behaviors. This research provides a basis to compare the moral thinking in Western individualism and Confucian relationalism from the perspective of social psychology.

Hwang (1998) cited Gert's (1973) distinction between positive and negative duties to argue that corresponding to the emphasis on rights in Western ethics is a stress on the importance of negative duties, which require abstention from 
actions that harm other's rights. "Do not kill," "do not cheat," and "do not steal," are examples of negative duties. Violating moral codes of this category is socially condemned. As long as negative duties are not in conflict with others' rights, they can be followed strictly by anyone in any situation with regard to all other persons.

Positive duties are usually stated as maxims to guide action, such as "practice charity," or "help needy persons." Positive duties are duties of commission. But, in the Western morality of objective rationalism, there is no specification as to how many good deeds have to be performed or whom they are to benefit so that a maxim can be said to have been performed. Because it is impossible for an individual to practice any particular positive maxim all the time and with regard to everybody, the application of any positive maxim requires the actor to take into consideration all concrete conditions and to exercise powers of judgment with rationality. Thus, the practice of positive duties of commission is subject to an individual's right of choice. The individual has the right to decide to practice the maxim or not (Miller, 1994); it is not an enforced social demand. Individuals who decide to undertake an altruistic act may be admired for their virtue.

The duty-based ethics of Confucian relationalism provide a completely different arrangement. The moral discourse arguing for negative duties in Eastern moral systems includes such principles as the silver rule (do not do to others what you do not want to be done to you) proposed by the Confucian Way of Humanity. The negative duties proposed are not on the premise of protecting individual rights, but rather in consideration of maintaining social order or for religious reasons. For example, the act of killing others is prohibited because it violates the principle of benevolence (ren), a positive duty. Ren requires people to carry out their moral duty to significant others in their intimate society, and is the most fundamental moral rule for maintaining psychosocial homeostasis in Chinese society.

In contrast to the rights-based ethics of Western individualism, Confucian ethics have a mandatory feature that requires everyone to practice positive duties. Understanding that it would be difficult for an ordinary person with limited resources to practice the positive duty of benevolence by offering resources to everybody, Mencius proposed a rule of thumb: take care of your aged parents first, and then extend your care to aged people in general; look after your own children first, and then extend to others' children (The Works of Mencius, Chapter 1A: King Hui of Liang). Mencius likewise proposed a kind of hierarchical love with distinction: Love one's parents who are the origin of one's life first of all, then extend love to others in accordance with one's relationship (or degree of intimacy) with them.

This hierarchical love is called the principle of favoring the intimate in Confucian ethics. Confucian ethics also advocate the principle of respecting the superior. That is, the person in the superior position has different moral obligations and responsibilities from people in lower positions. Thus, Chinese morality contains a relational and therefore subjective component. The value of an act is 
based on its impact on significant relationships. According to the moral code associated with Chinese culture, people should act according to behavioral codes that define the relationships between them. Proper behavior varies with each circumstance, depending upon the relationships of those involved. Thus, wrong and right are socially defined. These two principles sharply contrast with Western ethics in which justice is conceptualized as equality and is to be uniformly applied to all individuals. For Westerners, individual responsibility for behavior is constrained by absolute moral principles of right and wrong that do not vary with the situation; right and wrong can be objectively defined and used to guide behavior.

\section{GUILT, SHAME, IDENTITY AND MORALITY}

The major features of identity for individuals within a particular culture are related to the major values of the culture that shape identity and thus to the moral system that supports these values (see Table 1). Guilt and shame are the glue that holds this relation in place. They provide the connection between identity and morality. Although identity and morality may combine together in different ways to form different cultural systems, the role of guilt and shame in terms of binding them together remains constant across cultures. However, the relation of guilt and of shame to identity and to morality and the function of each emotion is likely to vary with the specific cultural context.

In Western cultures individuals are understood to be generally responsible for their own behavior. As such, moral guidance must come from inside the individual as it is not the function of the group to provide it. Therefore, individuals are expected to internalize a sense of proper behavior in congruence with social norms, and to experience guilt when these norms are transgressed. Guilt with its emphasis on individual responsibility is the proper foundation for a moral system composed of individuals responsible for themselves (Bedford, 1994). Inherent in the ideology of individualism with its emphasis on rights is a basic reluctance to take responsibility for others. Rights do not impose obligations on other people except the negative kind. Individuals are free to follow their own inclinations within the limits of the law in consideration of the general welfare. Americans do not see themselves as automatically involved in social relationships that impose obligations not of their choosing. With less sense of responsibility for others, and little stimulus for emphasis on the common good or community occurs, and there is less basis for shame due to the state or actions of others. Individual identity for Americans is connected to use of guilt and objective morality as methods of social control. It is not similarly compatible with use of situational morality or shame.

In contrast, shame is a more effective means of social control in a system where maintaining harmony in relationships is valued over maintaining behavior according to an objectively defined right and wrong. One is liable to lose group 
status when judged by the group as having failed to fulfill a group requirement. Since one shares the point of view of the group, one will also judge oneself a failure. Revelation of a failure or a flaw in one's identity produces the experience of shame. Shame is also associated with the fear that one's inadequacies will result in rejection by or expulsion from the group. There is less need for objective moral guidelines to limit behavior when the natural social repercussions, rejection by the group and loss of personhood, are severe enough to discourage antisocial acts. Relational identity is conducive to shame as a method of social control.

Relational identity also makes it difficult to confer guilt in the objective sense as Westerners conceptualize it. Because the boundaries of personality extend beyond the individual, it is difficult to confer objective guilt on a single person when the identity of the individual is not contained within that person but in the person's relationships. Even if one can identify the individual who perpetrated the crime, responsibility for the crime extends beyond the single individual as will the consequences. For example, if a person commits a crime, then that person's parents will be held responsible for not teaching their child better. The parents will suffer socially for the crimes of the offspring. In traditional China, punishment for murder was meted out not only on the individual culprit, but also on all relatives as well, with severity correlated with the degree of relationship (Latourette, 1917). Further, the principle of respecting the superior defines ethical obligations in a hierarchy so that the relationships among the actors determine the appropriate course of action for a given situation. The consequence is that the proper, moral course of action is determined by the context of the situation and the arrangement of relationships among those involved. In sum, relational identity is necessarily connected to use of shame and situational morality as methods of social control. It is not similarly compatible with use of objective morality, and thus, guilt.

With this clarification of the differential relations of guilt and shame to morality and identity in Western and Confucian cultures, it is clear the literature on guilt and shame from Western countries can not provide a complete picture of the roles and functions of guilt and shame in Confucian cultures.

\section{GUILT AND SHAME IN CHINESE CULTURE}

Bedford (2002) conducted an ethnographic study to identify the Mandarin terms for guilt and shame and to establish clearly the dimensions of the experiences of guilt and shame including the characteristic patterns of behavior, transformation of self, and values highlighted by these emotional experiences for Chinese people. In the following, the framework developed in this article is applied to the different types of guilt and shame identified in order to provide a more complete picture of the functions of guilt and shame and their relation with identity and morality in Chinese culture. 
Table 1. Identity, Morality, Guilt, and Shame in Confucian and Western Cultures.

\begin{tabular}{|c|c|c|}
\hline & Confucian Relationalism & Western Individualism \\
\hline Identity & Relational Self & Individual Self \\
\hline Source of Responsibility & $\begin{array}{l}\text { Obligation to Relational } \\
\text { Other }\end{array}$ & Right (Freedom) of Choice \\
\hline Standard of Morality & $\begin{array}{l}\text { Subjective (Relational) } \\
\text { Morality }\end{array}$ & Objective Morality \\
\hline $\begin{array}{l}\text { Mechanism of Social } \\
\text { Control }\end{array}$ & Shame & Guilt \\
\hline
\end{tabular}

Table 2. Aspects of Guilt and Shame in Mandarin.

\begin{tabular}{|c|c|c|c|c|c|}
\hline Emotion & Target & $\begin{array}{l}\text { Transgression } \\
\text { issue }\end{array}$ & $\begin{array}{l}\text { Ways to } \\
\text { cause }\end{array}$ & $\begin{array}{l}\text { Audience } \\
\text { required }\end{array}$ & $\begin{array}{l}\text { Personal/ } \\
\text { universal }\end{array}$ \\
\hline $\begin{array}{l}\text { Nei jü } \\
\text { 內疚 }\end{array}$ & $\begin{array}{l}\text { Toward } \\
\text { others }\end{array}$ & $\begin{array}{l}\text { Obligation to other- } \\
\text { positive duty }\end{array}$ & $\begin{array}{l}\text { Own } \\
\text { behavior }\end{array}$ & No & Personal \\
\hline $\begin{array}{l}\text { Zui e gan } \\
\text { 罪惡感 }\end{array}$ & $\begin{array}{l}\text { About own } \\
\text { behavior }\end{array}$ & $\begin{array}{l}\text { Morality- } \\
\text { negative duty }\end{array}$ & $\begin{array}{l}\text { Own } \\
\text { behavior }\end{array}$ & No & Both \\
\hline $\begin{array}{l}\text { Fan zui gan } \\
\text { 犯罪感 }\end{array}$ & $\begin{array}{l}\text { About own } \\
\text { behavior }\end{array}$ & $\begin{array}{l}\text { Rule/law- } \\
\text { negative duty }\end{array}$ & $\begin{array}{l}\text { Own } \\
\text { behavior }\end{array}$ & No & Universal \\
\hline $\begin{array}{l}\text { Diu lian } \\
\text { 丢臉 }\end{array}$ & For self & Reputation- & Own/other & Yes & Both \\
\hline $\begin{array}{l}\text { Can kui } \\
\text { 慚愧 }\end{array}$ & Of self & Ideal-positive duty & Own & No & Personal \\
\hline $\begin{array}{l}\text { Xiu kui } \\
\text { 羞愧 }\end{array}$ & Of self & Personal identity & Own/other & No & Personal \\
\hline $\begin{array}{l}\text { Xiu chi } \\
\text { 羞恥 }\end{array}$ & $\begin{array}{l}\text { Of self/for } \\
\text { other }\end{array}$ & $\begin{array}{l}\text { Shared identity- } \\
\text { positive or negative } \\
\text { duty }\end{array}$ & Own/other & No & Universal \\
\hline
\end{tabular}

Note. Modified from Bedford, O. (2002). The individual experience of guilt and shame in Chinese culture. Manuscript submitted for publication.

Three main types of subjective guilt were identified (nei jüu, zui e gan, and fan zui gan) along with four types of shame (diu lian, can kui, xiu kui, and xiu chi) (see Table 2).

Nei juu is the feeling of failure with respect to personal responsibilities. One feels one has not fulfilled an obligation, whether the other person thinks so or not. The duty-based morality of Confucianism entails the obligation to practice benevolence to others. A person's moral performance is evaluated in terms of willingness to help others. The broader the scope of practicing benevolence, the higher one's moral performance is considered to be. If one fails to uphold one's obligations and negative consequences happen to the person who asked for help, one may suffer from a feeling of nei jü. 
Because nei ju is caused by a failure to practice positive duties, it is essentially a personal guilt in two ways. First, it concerns only self-expectation and selfdemands. One does not necessarily require others to have the same obligations. Nor can it be imposed on another person as it is aroused only through one's own actions or lack thereof. Secondly, it is always felt towards other people for violating the deservedness of another or failure to uphold obligations to others. Nei jiu may occur even if one does not have the capacity to fulfill the obligation, but feels one ought to have it.

Zui e gan arises through violation of negative duties and involves the feeling of having done something terribly wrong. It is only aroused in relation to one's own behavior, or events for which one takes personal responsibility. It can be felt with respect to harm done to others, although it is not really experienced toward others, as is the case with nei juu. The central issue is not the harm done to the other person - it is the fact of the transgression of one's personal morality: what the self has done. It is in some ways quite similar to the Western conception of moral guilt - although there is an important difference.

In the first section of this article, it was noted that the silver rule advocated by Confucians implies negative duties. However, the silver rule is not exactly the same as the negative duties of the Western morality of rationalism. According to Kant (1797), there is a single categorical imperative applicable to all rationalists: act so as that the outcome of one's conduct is the universal will. In contrast, an individual following the silver rule must rely on personal feelings, affections, dispositions, or preferences, which may not be applicable to all others. The silver rule may be considered merely a subjective principle. Thus, moral guilt may be experienced over transgressions specific to the individual. The universal element present in the Western conception of moral transgression is not a necessary component of the Confucian conception.

Literally translated, fan zui gan is the feeling of breaking a law. It is the guilt experienced with committing a crime or breaking a rule and generally entails violation of negative duties, much as in Western cultures. Whereas nei jiu arises with respect to internal feelings of obligation and responsibility, fan zui gan is experienced generally in relation to externally defined obligations the individual recognizes as ones to which everyone ought to adhere. Fan zui gan is an impersonal guilt. Not felt toward people, it is merely the internal recognition of breaking a requirement.

Diu lian is literally translated as loss of face. In traditional Confucian societies where one's behaviors are constantly evaluated by others, lian or face refers to one's dignity, self-respect, feeling of social concern, and ability to fill social obligations in front of other people. It is a social product accorded by others. Although gain and loss of lian is impacted by one's own conduct, eventually it is determined and judged by other people. Diu lian entails the feeling of not having lived up to standards or values. These are not the so-called negative duties in the 
Western sense, which are the standards or values that one holds with regard to all people; they are not part of a universal standard for being a good or worthy human being. Rather, these are the subjective standards that individuals hold for themselves and the standards they recognize that other people have come to expect them to uphold in order to maintain their reputation, or the reputation of persons of their status. Since Confucian ethics emphasize the principle of respecting the superior, a person with high status should live up to higher social expectations. The higher a person's status, the more vulnerable that person is to losing lian. As mentioned, because Confucians conceptualize a person's life is as an inheritance from one's parents and ancestors, one's whole family is conceptualized as a great self and the boundaries of the self extend to include family members and significant others. Diu lian may be experienced either because of one's own behavior or because of that of friends or family to whom one's reputation is tied.

Can kui is the shame that comes from failing to attain one's best or the ideal state, and may often be connected to failure to carry out a positive duty. Can kui is not a strong feeling, probably because the violations are more a lack of action than commission of an inappropriate action, and involve failing to attain an ideal state, rather than the actual transgression of a standard. One has not done something that it would have been better to do, and that could have been done. Often one was prevented by of lack of time, or resources, or interest. More than that the ideal could have been attained, it is felt that in failing one has let others down or inconvenienced them. Can kui only occurs as the result of one's own behavior, or lack thereof. It cannot be imposed on another. Feelings of can kui do not call one's identity into question. Instead, they serve as a reminder of the bounds of identity. If the can kui event happens too often, then a greater shame will be felt, as one realizes that one really cannot attain the ideal.

Xiu kui can be a strong feeling of shame related to the conceptualization of oneself as a person. In xiu kui one has discovered a negative aspect of oneself, and this negative aspect has harmed others. No audience is required to experience it. Self-revelation is sufficient. It results in the feeling of a heavy weight or hei dien (stain) on the heart and brings thoughts of how to improve and resolve to change for the better in the future. Like nei jü, xiu kui is a strong personal feeling in two ways. First, it concerns only one's own self-assessment. Second, more than being just a feeling of shame of oneself, xiu kui means recognizing that one has harmed another person, although it differs from nei juu in that it is not felt towards the people one has harmed, but in recognition of one's own failings.

Xiu chi can be the strongest of the emotions under consideration. At its strongest is the feeling of having a hei dien (stain) on one's face, such that anyone who sees one will immediately know of one's shame and condemn one. One feels inadequate as a human being. A person experiencing xiu chi wants to avoid all contact with others, preferring to hide at home. This desire to eliminate contact 
stems from the fear that others will learn of the shameful event if they do not already know about it. Xiu chi is a more general type of shame than xiu kui, and is not personal. One does not feel xiu chi for hurting others; one feels xiu chi in recognition of one's own damage. It is tied to the awful realization of how others will see one; that they will know how one really is, and it is not how they or one thought one to be.

Xiu chi is about the transgression of identity: both one's own and other people's. Chinese people experience themselves as members of a group (great self or $d a$ wo) to a greater extent than Western people do. A large part of their identity is concerned with their relationships to those around them. When one transgresses this shared identity so that one's acts threaten the identity of other people, or when the part of one's identity that overlaps with other people's is threatened, then one experiences xiu chi. This is in contrast to xiu kui in which the shame is personal and arises from the awareness of the consequences of one's failure in having hurt others.

\section{GUILT, EAST AND WEST}

Similar to the Western concept of guilt, the three types of Chinese guilt all include a sense of responsibility, meaning they occur only in connection with what one demands and expects of oneself. Consistent with the Confucian ethics that advocate a moral system constructed on subjective standards of benevolence, if one does not accept a particular responsibility or obligation, one will not experience guilt over its transgression. As with Western cultures, a person cannot impose guilt feelings on another.

The three Mandarin terms for guilt allow for differentiation of among alternate types of responsibility. Nei jü highlights failure in positive duties that one imposes on oneself but not necessarily on other people. Fulfillment of duty in Confucian cultures is highly valued by the society, as it supports and maintains harmony between people, thereby protecting the stability of society. Individualistic cultures have less need to emphasize this type of guilt with a special term as the requirements for positive duties are not emphasized by the culture.

Zui e gan is connected to moral responsibility. Personal morality reflects one's understanding of how the world functions, and one's place in it. Zui e gan protects one's moral system, and so gives a sense of identity and stability to the individual by providing a sense of what should and should not happen. It is broader than Western moral responsibility, which is generally limited to negative duties, as it encompasses transgressions of either negative or positive duties such as violation of the silver rule or a failure to fulfill one's obligations. It includes the notion of responsibility and obligation to others, since both duty and obligation are part of Confucian morality, although it is not limited to obligations to people. 
Fan zui gan concerns social responsibility. As a member of society one should obey the rules established for everyone's benefit. Fan zui gan is experienced only for oneself in response to one's own transgressions of negative duties. The obligations originate from an external source, and are generally understood to apply universally. The function of fan zui gan is to protect society from those who would violate its regulations and laws. It protects the boundaries of society. This type of guilt is the most similar to Western conceptualization of nonreligious guilt.

Not only are finer discriminations in types of guilt possible in Mandarin than English, but the range of triggers for guilt appears to span a broader range in Chinese than Western culture. For example, nei jiu differs from the Western sense of guilt in that it can be aroused with respect to abilities that one does not have. This was also the case with the Japanese sense of guilt in which feelings of responsibility can be aroused without a transgression having occurred (Lebra, 1988). Guilt in the West does not usually occur with respect to capacities that one does not hold because Westerners do not usually feel morally obligated to possess particular capabilities (Bedford, 1994). In Confucian cultures, however, the sense of duty and obligation to family and group is much more strongly experienced and does contain a moral component that can extend to capabilities.

\section{SHAME, EAST AND WEST}

As with the Western conceptualization, the central issue of the shame emotions is identity. Whenever identity is threatened, shame is experienced. However, the aspect of the identity that is threatened in each case is different. With diu lian it is one's public identity, one's reputation that is transgressed. Can kui is caused by jeopardizing one's personal ideals. Xiu kui is due to threats to private identity, one's self-picture. Xiu chi is both public and private; one's identity in society is threatened.

The central difference between American and Chinese in self-concept may lead to a differential sensitivity to shame. Compared to Americans, a greater proportion of the identity of a Chinese person is dependent on relationships with other people with the result that to a greater extent than Americans, Chinese people are sensitive to being personally shamed by actions (or lack of action) on the part of others. When other people's actions infringe upon their sense of identity and order, it is enough to arouse a feeling of shame.

Unlike the Western experience, shame in Confucian cultures can be connected to morality, particularly the failure to fulfill positive duties. For Chinese, maintaining one's place or identity in the social hierarchy is a duty which is connected to moral belief since the social hierarchy is part of the natural cosmic order (Hwang, 2001b). Cultural differences in the nature of morality associated with the experience of shame are relevant to variations in the experience and 
function of the emotion. For example, in Chinese it is possible to make a distinction between public shame and private shame that is not made in English. Xiu kui results in a feeling of a stain on the heart (internal and private), while xiu chi results in the feeling of having a stain on the face (external and public). Given that a number of studies have found shame to be damaging to the individual and to social relationships, it seems possible that these different types of shame could have a differential effect.

\section{CONCLUSION}

This study provides support for the hypothesis that not only are the situations that arouse the affects of guilt and shame different for Chinese and Americans, the actual experience of the emotion differs as well, since the Chinese make discriminations that Americans do not make. Cultural context is necessary for understanding the role each emotion is likely to play and how it relates to identity and morality.

Several important avenues for future research arise with this new framework for understanding guilt and shame. First, it is possible that despite a lack of vocabulary to distinguish the various types of guilt and shame, Americans still experience different types of guilt and shame. Evidence supporting this hypothesis with respect to guilt already exists. Three different kinds of guilt (personal, impersonal, and trust violation guilt) reflecting the categories of arousal situations for a subjective guilt experience were revealed in a cluster analysis of a guilt and shame scale (Harvey \& Bedford, 1990; Gore \& Harvey, 1995). Studies have also shown that Americans differ in their proneness to experience a particular type of guilt (Johnson, Kim, \& Danko, 1989). This variability is related to such factors as the individual's belief system, religious orientation, and parent-child relationships (Bedford, 1990; Harvey \& Bedford, 1990). Future research might include identifying whether different categories of shame exist for Americans. Existence of different categories of shame allows for the possibility that the categories are differentially linked to the negative impact of shame on individual development and social relations cited at the beginning of this study. That is, perhaps only specific subcategories of shame are responsible for the negative outcomes.

Second, it seems possible that some experiences interpreted as shame by Chinese people could be experienced or labeled as guilt by Westerners or vice versa. A similar phenomenon has been described with respect to Japanese culture. Japanese tend to stress guilt feelings when speaking about their emotions, so that what is likely to be experienced as shame may therefore be talked about and thought about as guilt (Lebra, 1973). This occurs because shame implies an egocentric concern for self-image, while guilt entails a more allocentric concern for the consequences of one's behavior on other people. Since the value of 
empathizing with others is instilled in Japanese people from a very early age, Japanese people are more likely to admit to, and have a preference for experiencing guilt rather than shame. In this study, can kui, which is generally aroused over failure to fulfill a positive duty, may be a candidate for mislabeling. It is a type of shame that cannot be imposed on others. That is, like guilt and unlike other forms of shame, can kui requires a feeling of personal responsibility and control. A Western person experiencing this type of shame might be tempted to label it guilt, even if personal identity is threatened in the experience. Conversely, it may be possible that can kui revolves more around behavior than identity even for Chinese people, and the feelings that arise are labeled shame instead of guilt because of the predominance of shame in Chinese culture.

One possible implication of mislabeling to be explored in future research with American subjects would be whether previous studies have labeled some types of shame as guilt, contributing to the evidence for the positive effects of guilt, or to the lack of evidence for the beneficial effects of some types of shame in particular contexts. Future research on guilt and shame might include verification of the different types of guilt and shame and the issues over which they are aroused. For example, research conducted in Chinese culture might include quantitative verification of the ethnographically derived descriptions of guilt and shame provided by Bedford (2002), and could examine whether the situations labeled as shame, particularly can kui, all involve challenges to identity rather than behavior.

In conclusion, the framework offered in this article may be used to analyze the specific mentalities of people in a given culture, and thus is a tool for indigenous psychological research. Measures of guilt and shame sensitive to the peculiarities of a particular culture may not only provide insight into the functioning of these emotions within the culture under study, but also suggest avenues of research in other cultures in which the concepts are less well-developed. For example, an indigenous study of shame in Chinese culture may result in insights of relevance to American culture, where the concept of shame is less developed, and thus more difficult to examine. The framework also highlights the universal aspects of guilt and shame: their relation to identity and morality. As such, this framework should also be useful in developing measures of guilt and shame appropriate for conducting cross-cultural research, a goal we intend to work toward in future research.

Olwen Bedford, Ph.D., M.B.A.

Kwang-Kuo Hwang, Ph.D.

Indigenous Research Institute: Department of Psychology

South Building Room 103

National Taiwan University

Roosevelt Road, Section 4, \#1

Taipei 106 Taiwan

olwenb@yahoo.com 


\section{REFERENCES}

Abel, E., and Gecas, V. (1997). Guilt, shame and family socialization: A retrospective study. Fournal of Family Issues, 18 (2), 99-123.

Babcock, M., and Sabini, J. (1990). On differing embarrassment from shame. European Fournal of Social Psychology, 20, 151-169.

BEDFord, O. (1990). Guilt, shame and religious orientation. Unpublished Master's Thesis. University of Colorado, Boulder, Colorado.

BeDford, O. (1994). Guilt and shame in American and Chinese culture. Unpublished Doctoral Dissertation. University of Colorado, Boulder, Colorado.

BEDFord, O. (2002). The individual experience of guilt and shame in Chinese culture. Manuscript submitted for publication.

Benedict, R. (1947). The chrysanthemum and the sword. London: Secker and Warburg.

Cook, D. (1996). Empirical studies of shame and guilt: The internalized shame scale. In D. Nathanson (ed.), Knowing feeling: Affect, script, and psychotherapy (pp. 132-165). New York: W. W. Norton.

Creighton, M. (1988). Revisiting shame and guilt cultures: A forty-year pilgrimage. Ethos, 18, 279-307.

DeRivera, J. (1984). The structure of emotional relationships. Review of Personality and Social Psychology, 5, 116-144.

DeVos, G. (1974). The relation of guilt toward parents to achievement and arranged marriage among Japanese. In T. Lebra, \& L. Lebra (eds). Fapanese culture and behavior: Selected readings. Honolulu, HI: University Press of Honolulu.

Dworkin, R. (1977). Taking rights seriously. Cambridge, MA: Harvard University Press.

Gert, B. (1973). The moral rules. New York: Harper \& Row.

Gore, E., and Harvey, O. (1995). A factor analysis of a scale of shame and guilt: Dimensions of Conscience Questionnaire. Personality and Individual Differences, 19 (5), $769-771$.

Hamaguchi, E. (1982). Kanjinshugi no shakai nihon. [Japan, Society of Contextualization]. Tokyo: Tokyokeizai.

Harvey, O., and Bedford, O. (1990). Relationship of parental discipline, belief system and proneness toward guilt and shame and religious orientation. Paper presented at the annual meeting of the Society for the Scientific Study of Religion, Arlington, Va.

Hofstede, G. (1980). Culture's consequences. Beverly Hills, CA: Sage.

Hultberg, P. (1988). Shame: A hidden emotion. Fournal of Analytical Psychology, 33, 109126.

HwANG, K.K. (1995). Knowledge and action: A social-psychological interpretation of Chinese cultural tradition (in Chinese). Taipei: Psychological Publishers.

Hwang, K.K. (1998). Guanxi and mientze: Conflict resolution in Chinese society. Intercultural Communication Studies, 3 (1), 17-37.

HwANG, K.K. (2000). Chinese relationalism: Theoretical construction and methodological considerations. Fournal for the Theory of Social Behavior, 30 (2), 155-178.

Hwang, K.K. (2001a). Morality: East and West. In N.J. Smelser (ed.), International Encyclopedia of the Social and Behavior Science. Amsterdam: Pergamon.

Hwang, K.K. (2001b). The deep structure of Confucianism: A social psychological approach. Asian Philosophy, 11 (3), 179-204.

Izard, C. (1977). Human emotion. New York: Plenum.

Johnson, R., Kim, R., and Danko, G. (1989). Guilt, shame, and adjustment: A family study. Personality and Individual Differences, 10, 71-74.

Kant, I. (1797/1963). Groundwork of the metaphysic of morals. (H.J. Paton, Trans. and analyzed). New York: Harper \& Row. 
Kaufman, G. (1989). The psychology of shame: Theory and treatment of shame-based syndromes. New York: Springer.

KLuckhohn, C. (1960). The moral order in the expanding society. In C. Kraeling \& R. Adams (eds), City Invincible. Chicago: University of Chicago.

Kонкi, A. (2002). The relationship of guilt and shame to mental health. Fapanese fournal of Health Psychology, 14 (2) 24-31. [In Japanese].

Lansky, M. (1984). Shame and domestic violence. In D. Nathanson (ed.), The many faces of shame. New York: Guilford.

Latourette, K. (1917). The development of China. Boston: Houghton Mifflin Co.

Lebra, L. (1988). Comprehensive justice and moral investment among Japanese, Chinese, and Koreans. The Fournal of Nervous and Mental Disease, 157, 278-291.

Leith, K.P., and Baumeister, R.F. (1998). Empathy, shame, guilt, and narratives of interpersonal conflicts: Guilt-prone people are better at perspective taking. Fournal of Personality, 66 (1), 1-37.

Lewis, H. (1971). Shame and guilt in neurosis. New York: International Universities.

Lewis, H. (1987). Shame and the narcissistic personality. In D. Nathanson (ed.), The many faces of shame. New York: Guilford.

Lewis, M. (1997). The self in self-conscious emotions. In J. Snodgrass, R. Thompson (eds), The self across psychology: Self-recognition, self-awareness, and the self-concept. Annals of the New York Academy of Sciences, Vol. 818 (pp. 119-142). New York: New York Academy of Sciences.

Lindsay-Hartz, J. (1984). Contrasting experiences of shame and guilt. American Behavioral Scientist, 27, 689-704.

Lutwak, N., Panish, J., Ferrari, J.R., and Razzino, B.W. (2002) Shame and guilt and their relationship to positive expectations and anger expressiveness. Adolescence, $\mathbf{3 6}$ (144), 541-653.

Lutwak, N., Razzino, B.E., and Ferrari, J.R. (1998). Self-perception and moral affect: An exploratory analysis of subcultural diversity in guilt and shame emotions. Fournal of Social Behavior and Personality, 13 (2), 333-348.

Luyten, P. Corveleyn, J., and Fontaine, J. (1998). The relationship between reliogiosity and mental health: Distinguishing between shame and guilt. Mental Health, Religion and Culture, 1 (2), 165-184.

Markus, H.R., and Kitayama, S. (1991). Culture and the self: Implications for cognition, emotion, and motivation. Psychological Review, 98, 224-253.

Mead, M. (ed.) (1937). Cooperation and competition among primitive peoples. New York: McGrawHill.

Miller, S. (1994). The shame experience. Hillsdale: The Analytic Press.

Morrison, A. (1983). Shame, the ideal self and narcissism. Contemporary Psychoanalysis, 19, 295-318.

Niedenthal, P., Tangney, J., and Gavanski, I. (1994). "If only I weren't" versus "If only I hadn't": Distinguishing shame and guilt in counterfactual thinking. Fournal of Personality and Social Psychology, 67 (4), 585-595.

Piers, G., and Singer, M. (1953). Shame and guilt. Springfield, IL: International University Press.

SAkuta, K. (1967). Hago no bunka saiko. [Shame culture reconsidered.] Tokyo: Chikuma Shebo.

Scheff, T. (1988). Shame and conformity: The deference emotion system. American Sociological Review, 53, 395-406.

Szeto-Wong, G. (1997). Relation of race, gender, and acculturation to proneness to guilt, shame, and transferred shame among Asian and Caucasian-Americans. Dissertation Abstracts International: Section B: the Sciences E Engineering, 58 (6-B), 3328. 
Tangey, J. (1998). How does guilt differ from shame? In J. Bybee (ed.), Guilt and children (pp. 1-17). San Diego, CA: Academic Press.

TANGEY, J. (2001). Constructive and destructive aspects of shame and guilt. In A. Bohard \& D. Stipek (eds), Constructive and destructive behavior: Implications for family, school, and society (pp. 127-145). Washington DC: American Psychological Association.

TAngey, J. (2002). Self-conscious emotions: The self as a moral guide. In A. Tesser \& D. Stapel (eds), Self and motivation: Emerging psychological perspectives (pp. 97-117). Washington DC: American Psychological Association.

Tangey, J., and Dearing, R.L. (2002). Shame and guilt. Emotions and social behavior. New York: The Guilford Press.

Thrane, G. (1979). Shame and the construction of the self. The Annual of Psychoanalysis, 7, 321-341.

Triandis, H.C. (1988). Collectivism and individualism: A reconceptualization of a basic concept in cross-cultural psychology. In G.K. Verma \& C. Bagley (eds), Personality, attitudes and cognitions (pp. 60-95). London: Macmillan.

Triandis, H.C. (1993). Collectivism and individualism as cultural syndromes. Cross-cultural Research, 27, 155-180.

Triandis, H.C. (1995). Individualism and collectivism. Boulder, CO: Westview Press.

Triandis, H.C., Bontempo, R., Villareal, M.J., Asai, M., and Lugca, N. (1988). Individualism and collectivism: Cross-culture perspectives on self-in-group relationships. Fournal of Personality and Social Psychology, 54, 353-338.

WALter, J.L. (2002). The emergence of the capacity for guilt in preschoolers: The role of personal responsibility in differentiating shame from guilt. Dissertation Abstracts International: Section B: the Sciences \& Engineering, 62 (8-B), 3831.

Wharton, B. (1990). The hidden face of shame: The shadow, shame, and separation. Journal of Analytical Psychology, 35, 279-190.

Wurmser, L. (1981). The mask of shame. Baltimore: Johns Hopkins University. 